\title{
Erratum to: Poster: Internal medicine, graded care hospitals and the heterogeneity of patients at admission
}

\author{
G. Grignani $\cdot$ S. Panzeri $\cdot$ A. Sottocornola $\cdot$ \\ G. Casella $\cdot$ M. Vanoli
}

Published online: 27 March 2011

(C) SIMI 2011

Erratum to: Intern Emerg Med (2010) 5 (Suppl 2):S129-S277

DOI 10.1007/s11739-010-0506-2

The four histograms which have been placed in Page S175 in original publication should be under the abstract titled "Internal medicine, graded care hospitals and the heterogeneity of patients at admission" in Page S174; they should be followed by the paragraph starting with "At day 3 after admission, ....." and references, both in Page S175 in original publication.

The online version of the original article can be found under doi:10.1007/s11739-010-0506-2.

G. Grignani - S. Panzeri · A. Sottocornola - G. Casella •

M. Vanoli $(\bowtie)$

Department of Medicine, P.O. Merate, A.O. Lecco, Italy

e-mail: m.vanoli@ospedale.lecco.it 